\title{
Transferable Ageing Provisions IN INDIVIDUAL HEALTH INSURANCE CONTRACTS
}

\author{
FLORIAN BAUMANN \\ VOLKER MEIER \\ MARTIN WERDING
}

CESIFo Working PAPER No. 1116

CATEGORY 9: INDUSTRIAL ORGANISTION

JANUARY 2004

\footnotetext{
An electronic version of the paper may be downloaded

- from the SSRN website:

- from the CESifo website:

www.SSRN.com

www.CESifo.de
} 


\title{
Transferable Ageing Provisions in INDIVIDUAL HEALTH INSURANCE CONTRACTS
}

\begin{abstract}
We consider lifetime health insurance contracts in which ageing provisions are used to smooth the premium profile. The stock of capital accumulated for each individual can be split into two parts: a premium insurance and an annuitised life insurance, where the latter would be transferable between insurers without triggering premium changes through risk segmentation. In a simulation based on German data, the transferable share declines in age. It is smaller for women than for men, and it falls with an increasing age of entry into the contract.
\end{abstract}

JEL Classification: D91, G22, I18.

Keywords: health insurance, lifetime contracts, ageing provisions premium insurance, simulations.

\author{
Florian Baumann \\ Department of Economics \\ University of Mainz \\ D-55099 Mainz \\ Germany \\ baumanf@uni-mainz.de
}

\author{
Volker Meier \\ Ifo Institute for Economic Research and \\ CESifo \\ Poschingerstr. 5 \\ D-81679 Munich \\ Germany \\ meier@ifo.de
}

Martin Werding

Ifo Institute for Economic Research and

CESifo

Poschingerstr. 5

D-81679 Munich

Germany

werding@ifo.de 


\section{Introduction}

In Germany and Austria, private health insurance contracts are typically purchased by individuals and are made on a lifetime basis. A capital stock is built up so as to keep the annual premium constant during the contract period. One of the insurer's obligations involved in these contracts is making ageing provisions. These are accumulated in order to deal with an increase in expected benefits which can be attributed to two major reasons. First, even low risks experience a continuous deterioration of their health status over the life cycle. Second, the fraction of individuals who have turned into high risks rises as a birth cohort grows old. The latter phenomenon would be reflected in sharply increasing premiums if contracts were written on an annual basis. But, as insurers are neither allowed to terminate the contract nor to change the premium according to individual experience rating, lifetime contracts protect the insured against this premium risk. ${ }^{1}$ So far, individuals who would like to switch to another insurer are not entitled to take any fraction of their ageing provision with them. Since this involves substantial losses already after a few years of duration of the contract, the insured are effectively tied to their insurer, which hampers competition. In fact, Dowd and Feldman (1992), and Hendel and Lizzeri (2003) consider the fear of being locked into a long-term contract with an insurer providing an unpleasant service as a major obstacle against establishing long-term health insurance contracts in the US. However, transferring total ageing provisions to the new insurer would trigger a process of risk segmentation. Individuals who still represent low risks would switch to a new insurer in order to save premiums. For the remaining insured cohort premiums would have to be increased.

This paper explores how a scheme of transferable ageing provisions can be designed without imposing disadvantages on those who stay with the initial insurer. The basic idea is to reconstruct German-style, lifetime insurance contracts through a series of annual contracts with guaranteed renewability (Pauly et al. 1995) that are supplemented by an annuity insurance to smooth the premium profile. The capital stock accumulated for the annuity then constitutes the transferable share of total ageing provisions. In a com-

\footnotetext{
${ }^{1} \mathrm{By}$ international standards, these features are next to unique. In most countries, unfunded systems of public health care or public health insurance solve the premium risk problem. In countries where private health insurance has a considerable market share, like in the US, an analogous, but limited, kind of cover is often provided through employerbased group insurance contracts.
} 
petitive insurance market, healthy individuals could then switch to other insurers without incurring losses that are prohibitively high. At the same time, individuals facing higher health risks would be protected against the financial consequences of low risks systematically leaving the pool. Such a solution is efficient if transfers that are differentiated by health status cannot be used and low risks and high risks are sufficiently distinct (Meier, 2003).

If transfers could be made contingent on the state of health of the switching individual, it would be even better to assign higher transfers to high risks who want to terminate an unpleasant relationship with their insurer, in line with Cochrane's (1995) idea of time-consistent health insurance. Ideally, the transfer could then subsidize higher premiums to be paid to the new insurer such that high risks also would not incur any financial loss when switching. Designing such a scheme in practice is however difficult. In particular, if the health prospects of an individual cannot be verified at court at a low cost, there would be a substantial risk of wasteful disputes between old and new insurer. The new insurer would tend to ask for a high transfer, declaring that the insured constitutes a high risk, while the old insurer could save money if the individual is assessed as being healthy.

Using official German data on mortality and expenditure in private health insurance and setting plausible parameters for transitions between health states, we find that the share of ageing provisions that is transferable is generally positive until death. This result goes along with the finding in Herring and Pauly (2003) that the premium profile in health insurance contracts with guaranteed renewability is typically increasing in age. As pointed out earlier by Pauly et al. (1995) and Frick (1998), this conclusion is not immediate from theoretical considerations alone. In guaranteed renewable contracts, the premium consists of two components, reflecting expected health care costs of a low risk in the current year and a contribution to the premium insurance. The latter captures the increase in the present value of expected benefits when turning into a high risk during the year. This present value becomes small when the remaining life expectancy gets short. It is therefore easy to construct examples where the total premium declines in age. Smoothing the premium profile would then involve a reverse annuity, implying negative transfers of provisions, or exit premiums, for those who would like to leave their insurer.

Our paper shows how the decomposition of ageing provisions could work in practice and demonstrates that the share of transferable ageing provisions generally decreases in age. This is due to the fact that the share of recipients 
in the premium insurance increases over time. Consequently, the capital stock per surviving insured that can be attributed to the annuity peaks several years earlier than the stock that funds the premium insurance. In our baseline simulation where a male cohort is considered that enters the health insurance contract at age 30 and dies out 70 years later, the share of transferable ageing provisions falls from 96 per cent after one year to about 27 per cent after 69 years. The absolute amount of the transfer peaks after 30 years when individuals are aged 60 .

The corresponding share is smaller for women than for men. This is due to the fact that the profile of annual average benefits is less steep for women. Benefits exceed those for men before individuals reach the retirement age, while they are lower than the corresponding values for males afterwards. Therefore, the amount of ageing provisions for women falls short of those for men and the role of the annuity in smoothing total premiums is less pronounced. Similarly, entering the contract at higher age implies that the difference between maximum and minimum expected annual benefits goes down. Since some years are missing that are relatively inexpensive, the weight of the annuity insurance again becomes smaller at any given age.

The remainder of the paper is organized as follows. In section 2, we introduce the model and the parameters being set to run the simulations. In section 3 , we describe the data and discuss some of the methodological issues involved. The results of the simulations are presented in section 4. Section 5 discusses the main findings and possible extensions.

\section{The model}

\subsection{Structure and parameters}

The model considers individual lifetime health insurance contracts. At any age $x$ the insured population can be divided into two risk groups, low risks

$(l)$ with a time series of expected annual health care costs $K_{x}^{l}$ and high risks $(h)$ with expected health care costs $K_{x}^{h}$, where

$$
K_{x}^{h}=f_{x} K_{x}^{l} \quad \text { with } \quad f_{x}>1
$$

for $x=x_{0}, \ldots, \omega$. Because of risk screening by the insurer, all insured represent low risks at the age of entry $x_{0}$. At the end of each year $x$, a fraction $\left(1-\lambda_{x}\right)$ of the low risks experiences a permanent deterioration of the health 
status. These individuals represent high risks from age $x+1$ until they die. Thus, a long-term risk arising from variations in expected health costs, being reflected in the cost factor $f_{x}$, is added to the short-term cost risk. Over time, individuals die with probability $w_{x}$ at the end of each year. The contract expires at the end of year $\omega$ when all members of the insured cohort will be dead. The evolution of the two risk groups $\left(l_{x}, h_{x}\right)$ is described by the equations (2) and (3):

$$
\begin{gathered}
l_{x+1}=l_{x} \lambda_{x}\left(1-w_{x}\right), \\
h_{x+1}=\left(h_{x}+l_{x}\left(1-\lambda_{x}\right)\right)\left(1-w_{x}\right) .
\end{gathered}
$$

Average expected benefits per insured at age $x, K_{x}$, are given by a weighted average of $K_{x}^{l}$ and $K_{x}^{h}$, with

$$
K_{x}=\frac{l_{x}+f_{x} h_{x}}{l_{x}+h_{x}} K_{x}^{l}
$$

To calculate the time schedules of insurance premiums we need to know the present values of expected benefits. With $i$ being the (time-invariant) interest rate, the present value of average health care costs at age $x, A_{x}$, is

$$
A_{x}=\frac{1}{l_{x}+h_{x}} \sum_{z=\mathbf{0}}^{\omega-x} K_{x+z}\left(l_{x+z}+h_{x+z}\right)(1+i)^{-z},
$$

which equals

$$
A_{x}=K_{x}+\frac{1-w_{x}}{1+i} A_{x+1} .
$$

The risk-specific values $A_{x}^{l}$ and $A_{x}^{h}$ can be computed in the same way as in equation (6). If we consider an individual who is currently a low risk, we have to take into account the possibility of a transition into the high-risk status:

$$
\begin{gathered}
A_{x}^{l}=K_{x}^{l}+\frac{1-w_{x}}{1+i}\left[\lambda_{x} A_{x+1}^{l}+\left(1-\lambda_{x}\right) A_{x+1}^{h}\right], \\
A_{x}^{h}=K_{x}^{h}+\frac{1-w_{x}}{1+i} A_{x+1}^{h} .
\end{gathered}
$$




\subsection{Level premium and ageing provisions}

Lifetime health insurance contracts in Germany have to be calculated in such a way that premiums stay constant during the whole contract period. Risk assessment only takes place at the beginning of the contract. In subsequent periods, the insurer must not adjust premiums according to individual experience rating; and he is not allowed to terminate the contract. This implies that the constant premium $\bar{P}_{x_{0}}$ which depends on the age of entry $x_{\mathbf{0}}$ has to be equal to the annualized present value of total health care costs expected at the beginning of the contract. Note that, due to risk screening by the insurer, all insured represent low risks at their age of entry. Therefore, $\bar{P}_{x_{0}}$ is given by

$$
\bar{P}_{x_{0}}=\frac{A_{x_{0}}}{a_{x_{0}}}=\frac{A_{x_{0}}^{l}}{a_{x_{0}}}
$$

where $a_{x}$ is the value of an annuity of one capt uring the probabilities of dying, with

$$
a_{x}=\frac{1}{l_{x}+h_{x}} \sum_{z=0}^{\omega-x}\left(l_{x+z}+h_{x+z}\right)(1+i)^{-z}=1+\frac{1-w_{x}}{1+i} a_{x+1} .
$$

Since expected health care costs rise with age, the level premium first exceeds the expected costs per insured. A capital stock, the ageing provision, is built up from the surpluses which will be used in subsequent periods to pay for the difference between increasing average benefits and constant premiums.

The evolution of the ageing provision per insured at the end of year $x, V_{x}$, is based on average expected benefits and can be described retrospectively or prospectively. Retrospectively, $V_{x}$ is given by the sum of all net-injections (i.e., annual premiums minus expected annual benefits), plus interest payments and redistributed ("bequeathed") ageing provisions of individuals of the same age cohort who have died in the year under consideration. Therefore,

$$
V_{x}=\left(V_{x-1}+\bar{P}_{x_{0}}-K_{x}\right) \frac{1+i}{1-w_{x}} .
$$

Prospectively, provisions are equal to the future net liabilities of the insurer. These can be derived from the difference between the present value of expected insurance benefits and the present value of expected premium payments per insured. Indeed, using equation (10) to rewrite the premium payment as

$$
\bar{P}_{x_{0}}=\bar{P}_{x_{0}}\left(a_{x}-\frac{1-w_{x}}{1+i} a_{x+1}\right),
$$


and isolating $K_{x}$ in equation (6), equation (11) can be transformed into

$$
V_{x}=\left(V_{x-1}+\bar{P}_{x_{0}} a_{x}-A_{x}\right) \frac{1+i}{1-w_{x}}+\left(A_{x+1}-\bar{P}_{x_{0}} a_{x+1}\right) .
$$

Starting with provisions of zero at the beginning of the contract $\left(V_{x_{0}-1}=0\right)$ and taking into account equation (9), it follows that

$$
V_{x}=A_{x+1}-\bar{P}_{x_{0}} a_{x+1} .
$$

If expected health care costs rise with age, ageing provisions are positive until the end of period $\omega$.

\subsection{The premium insurance}

The contractual structure described here can be seen as a combination of three single arrangements: a repeated short-term health insurance contract covering annual health costs year after year; a premium insurance meant to avoid variations in short-term insurance premiums that arise from changes in the risk classification of the insured; and an annuity contract that is used to smooth the premium schedule. The premium insurance deserves particular attention because it is the core element of the long-term relationship between insurer and insured. The premium risk arises from the possibility of a transition from the low to the high risk status during the contract period. It does not deal with variations in premiums due to increases in expected health costs for low risks growing old.

Pauly et al. (1995) describe a long-term health insurance contract which consists of the first two components, the short-term health insurance and the premium insurance. The resulting insurance contracts with guaranteed renewability cover the premium risk by offering a guaranteed premium profile that is independent of any changes in the risk status of the insured. The premium schedule $P^{G R}$ is constructed in a fashion that it never pays for a low risk to leave the insurer. In other words, the present value of premium payments does not exceed the present value of expected health care costs for a low risk at any point in time. Financing the higher costs of high risks is accomplished by introducing an element of front-loading. Formally, this element originates from the fact that the possibility of turning into a high risk is always reflected in the expected present value of benefits of a low risk. Risk-averse individuals will prefer such a scheme to an arrangement where short-term premiums vary with the current health status. 
The way in which contracts with guaranteed renewability are calculated is summarized in equation (15). In each period, the expected present value $(P V)$ of premium payments is equal to the present value of expected health costs of a current low risk: ${ }^{2}$

$$
E\left\{P V_{x}\left(P^{G R}\right)\right\}=A_{x}^{l} \quad \forall x=x_{0}, \ldots, \omega .
$$

As risk screening by the insurer implies that all insured are of the low-risk type when entering the contract, lifetime premium payments cover expected health costs in full. Decomposing the right-hand and left-hand side expressions in equation (15) yields

$$
\begin{aligned}
& P_{x}^{G R}+\frac{1-w_{x}}{1+i} E\left\{P V_{x+1}\left(P^{G R}\right)\right\} \\
= & K_{x}^{l}+\frac{1-w_{x}}{1+i}\left[\lambda_{x} A_{x+1}^{l}+\left(1-\lambda_{x}\right) A_{x+1}^{h}\right]
\end{aligned}
$$

and, therefore,

$$
P_{x}^{G R}=\underbrace{K_{x}^{l}}_{P_{x}^{S}}+\underbrace{\left(1-\lambda_{x}\right)\left[A_{x+1}^{h}-A_{x+1}^{l}\right] \frac{1-w_{x}}{1+i}}_{P_{x}^{P I}} .
$$

The premium $P_{x}^{G R}$ can be interpreted as the long-term risk equivalent premium of a low risk at age $x$ and consists of two parts. The first component, the expected short-term health care benefits of a low risk, represents the premium for short-term insurance, $P_{x}^{S}$. The second component, $P_{x}^{P I}$, is paid for the premium insurance. It is determined based on the probability of becoming a high-risk type during the period, multiplied with the loss should this actually happen. The latter is given by the present value of increased expected health care costs, which would be mirrored by higher premiums in a series of short-term contracts with experience rating. Note that, in our model, premiums are paid at the beginning of each period, while any changes in the health status occur at the end of the year - a timing which necessitates discounting the $P^{P I}$-term in equation (17). In contrast to the level premium,

\footnotetext{
${ }^{2}$ As Kifmann (2002) argues, a premium schedule satisfying $E\left\{P V_{x_{0}}\left(P^{G R}\right)\right\}=A_{x_{0}}^{l}$ and $E\left\{P V_{x}\left(P^{G R}\right)\right\} \leq A_{x}^{l}$ with strict inequality for some $x$ can also be interpreted as a scheme with guaranteed renewability. However, the construction in equation (15) is associated with the minimum front-loading element and enables us to isolate the premium insurance in a convenient fashion.
} 
the premium schedule of the insurance contract with guaranteed renewability is independent of the age at entry.

The additional premium payments $P_{x}^{P I}$ are used to accumulate a capital stock in order to finance the higher costs of the individuals who turn into high risks. The financial flows related to these funds can be interpreted as follows. In each period, all insured individuals pay contributions to the premium insurance. Accumulated funds are then used to offset the difference between benefits and premiums of high risks in short-term health insurance. At the end of each period $x$, total funds of the premium insurance, $V_{x}^{P I}$, amount to

$$
\begin{aligned}
V_{x}^{P I}= & \left(V_{x-1}^{P I}+\left(l_{x}+h_{x}\right) P_{x}^{P I}-h_{x}\left(K_{x}^{h}-P_{x}^{S}\right)\right)(1+i) \\
= & V_{x-1}^{P I}(1+i)+h_{x+1}\left(A_{x+1}^{h}-A_{x+1}^{l}\right) \\
& -h_{x}(1+i)\left[K_{x}^{h}-K_{x}^{l}+\lambda_{x} \frac{1-w_{x}}{1+i}\left(A_{x+1}^{h}-A_{x+1}^{l}\right)\right] \\
= & \left(V_{x-1}^{P I}-h_{x}\left(A_{x}^{h}-A_{x}^{l}\right)\right)(1+i)+h_{x+1}\left(A_{x+1}^{h}-A_{x+1}^{l}\right) \\
= & h_{x+1}\left(A_{x+1}^{h}-A_{x+1}^{l}\right) .
\end{aligned}
$$

The accumulated stock of capital equals the difference in the present values of future benefits and premium payments for all those who are currently high risks. In the framework of our model, the present value of premium payments coincides with the present value of expected health costs for low risks. It turns out that the construction of insurance contracts with guaranteed renewability is indeed robust with respect to risk segmentation. Even if all individuals of an age cohort who still represent low risks leave their initial insurer at the end of period $x$, there is no need to increase premiums for the remaining members of the cohort. The additional costs they are facing are fully covered by $V_{x}^{P I}$. On the other hand, high risks are tied to the old insurer. They would incur substantial financial losses when switching to another insurer, thereby forfeiting their claims against the old insurer's premium insurance.

\subsection{Annuities and the decomposition of ageing provi- sions}

In the calculations so far, premiums for contracts with guaranteed renewability are not constant over time. The time profile of premiums depends on the profiles of health care costs for low and high risks and on the probabilities of 
a transition from state $l$ to state $h$. In addition, it is influenced by the interest rate and the probabilities of dying. A premium that is entirely flat can be achieved by adding an annuitised life insurance that accumulates and decumulates another stock of capital. The resulting total premium is formally computed as the annualized present value of $P^{G R}$, the full premium profile for contracts with guaranteed renewability. It equals the level premium $\bar{P}_{x_{0}}$ :

$$
\bar{P}_{x_{0}}=\frac{E\left\{P V_{x_{0}}\left(P^{G R}\right)\right\}}{a_{x_{0}}}=\frac{A_{x_{0}}^{l}}{a_{x_{0}}} .
$$

Net injections into the annuity funds are given by the difference between the constant premium $\bar{P}_{x_{0}}$ and the premium schedule of contracts with guaranteed renewability. The amount of these funds per insured individual at the end of year $x, V_{x}^{A}$, can be computed in the same way as the total ageing provisions, that is,

$$
\begin{aligned}
V_{x}^{A} & =\left(V_{x-1}^{A}+\bar{P}_{x_{0}}-P_{x}^{G R}\right) \frac{1+i}{1-w_{x}} \\
& =E\left\{P V_{x+1}\left(P^{G R}\right)\right\}-\bar{P}_{x_{0}} a_{x+1} \\
& =A_{x+1}^{l}-\bar{P}_{x_{0}} a_{x+1} .
\end{aligned}
$$

The stock of capital related to the annuity equals the difference between the present value of expected premiums under guaranteed renewability, $P^{G R}$, which are equal to expected health care benefits of a low risk, $A_{x}^{l}$, and the present value of actual premium payments. Equation (20) does not rule out that the reserves of the annuity are negative at some point in time between $x_{0}$ and $\omega$. But if the $P^{G R}$-schedule predominantly rises with age, $V^{A}$ will always be non-negative. The annuity serves as a means to partly prefund the higher insurance premiums when the insured cohort grows old.

Since the level premium is the sum of the contributions to short-term health insurance, premium insurance and the annuity insurance, total ageing provisions can be decomposed into reserves related to the premium insurance and to the annuity. In order to do so, $V^{P I}$ has to be assessed on a per-capita basis. Then, adding up the reserves of premium insurance and the annuity leads to

$$
\begin{aligned}
\frac{V_{x}^{P I}}{l_{x+1}+h_{x+1}}+V_{x}^{A} & =\frac{h_{x+1}\left[A_{x+1}^{h}-A_{x+1}^{l}\right]+\left(h_{x+1}+l_{x+1}\right) A_{x+1}^{l}}{l_{x+1}+h_{x+1}}-\bar{P}_{x_{0}} a_{x+1} \\
& =A_{x+1}-\bar{P}_{x_{0}} a_{x+1}=V_{x}
\end{aligned}
$$


While the funds related to the premium insurance are ear-marked to be used for high risks who, due to fresh risk assessment, cannot change their insurer without incurring substantial financial losses, the funds of the annuity insurance serve both low and high risks alike. They could thus be transferred to a new insurer without harming those who stay with the old insurer.

\section{Data}

The data used for our simulations, covering mortality rates and average insurance benefits of the insured in German private health insurance, is taken from official German sources. The Federal Authority for the Supervision of Financial Services regularly publishes life tables and benefit statistics that have to be used by insurance companies when calculating their premiums. The life tables $(B A V, 2000)$ take into account that life expectancy is somewhat higher among the insured in private health insurance than in the general population. Benefit statistics (BaFin, 2002) are differentiated according to age, sex, and type of health care services (out-patient, hospital, and dental treatment). The information provided can thus be combined to form time profiles of total expected health costs for individuals who represent an "average risk" at each point in time during their life-cycle.

We consider a standard type of contract in which about 320 Euro in a given year have to be paid out of pocket for out-patient treatment, hospital treatment is covered at twin-room rates, and the copayment rate for dentures is around $25 \%$. Figure 1 shows the profiles of expected insurance benefits for both males and females aged 20 to 100 disregarding, for the moment, their survival probabilities. In the following, we will consider only individuals aged 30 and over. Since the regulatory framework in Germany requires employed individuals to stay with public health insurance until their earnings exceed about 150 per cent of average earnings, the majority of entrants into private health insurance is indeed around age 30 .

Usually, health insurers are rather successful in picking only individuals in good health when writing lifetime contracts. Later on, however, there will always be some members of the initial cohort whose health status deteriorates. These individuals are lifted to a higher profile of expected insurance benefits in each year that remains of their life span. For the purpose of our simulations, a distinction between just two types of risks, "low risks" and all kinds of "high" ones, is sufficient. A workable definition of "low" risks 


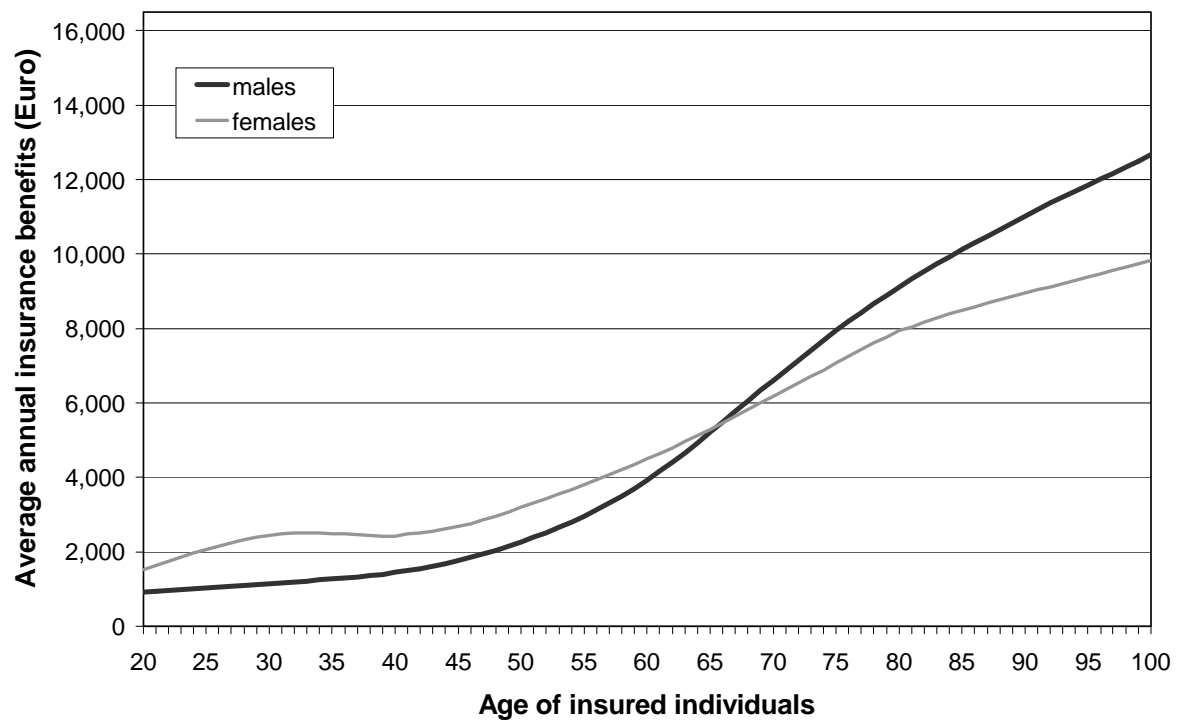

Figure 1: Average annual health insurance benefits

may be given as follows. A low risk is an individual who would be offered a health insurance contract at a standard rate that may be contingent on age and sex, but does not involve any risk-specific surcharge.

The data that is publicly available offers no information that could be exploited to differentiate average benefits by risk types. We therefore have to make some plausible assumptions in order to create risk-specific cost profiles. First, we assume that transitions always turn low risks into high ones, and that this happens at a rate which is increasing with age. In other words, we ignore the possibility of recovery in terms of expected health care costs. Also, we neglect the possibility that the hazard rate of becoming a high risk may actually decrease once individuals have survived until very high ages. In our simulation, the probability of leaving the good health status within the next year is less than .2 per cent for a 30-year old and increases to about 2 per cent when reaching age 99. For simplicity, we model the transition between these limiting values by a polynomial function ( $4^{\text {th }}$ degree) that rises rather sharply over the first twenty years, then levels out and starts rising again at age 85. For a cohort of individuals who enter a private health insurance contract as low risks at age 30 , this implies that among those who survive 
30.1 per cent have turned into high risks at age $60,60.2$ per cent at age 90 , and 67.4 per cent at age 100, that is, in the final year of our simulation.

Second, we need an assumption as to by how much expected health expenditure of a bad risk exceeds the corresponding value of a good risk. In our scenarios, it is 1.9 times higher for individuals aged 31 and 3 times higher for those aged 100 . Intermediate values are again imputed by a polynomial, $s$-shaped function ( $3^{\text {rd }}$ degree).

Given these specifications regarding the distribution of risk types and the cost differential, we can calculate time profiles of insurance benefits for both low and high risks starting from age 30 that are consistent with the profile of average costs taken from existing data. Before doing so, however, we have to adjust the data displayed in Figure 1 for the impact of successful risk selection by insurers on average health costs related to the early years of insurance. The original data covers 30 -year olds who entered a contract several years ago, already being hit by a deterioration of their health status with some probability. Thus, the average cost related to a cohort of fresh entrants aged 30 should be lower than the average value given by the data. We assume health costs for a cohort of low risks to be 24 per cent lower than those for the mixed group, phasing out this reduction by 2 percentage point a year over the first 12 years. This adjustment is only made to keep things as realistic as possible, while it does not at all affect the structure of our results.

Figure 2 exhibits the profiles for males obtained through these operations. They will enter the following simulations of lifetime health insurance contracts in an environment where contracts cannot be terminated by insurers and experience rating is ruled out.

Last, the real interest rate is set to 3.5 per cent throughout. All calculations refer to constant 2001 prices.

\section{Results}

In our simulations, we take as given the level and structure of expected insurance benefits, the probabilities of a change in health status and the mortality rates that have been introduced in the previous section. All figures refer to a scenario in which nobody leaves the original insurer. As a baseline case, we consider a cohort of males who enter private health insurance at age 30. We then turn to the case of females (age at entry is, again, 30) who face a time profile of health costs that differs substantially from the profile for 


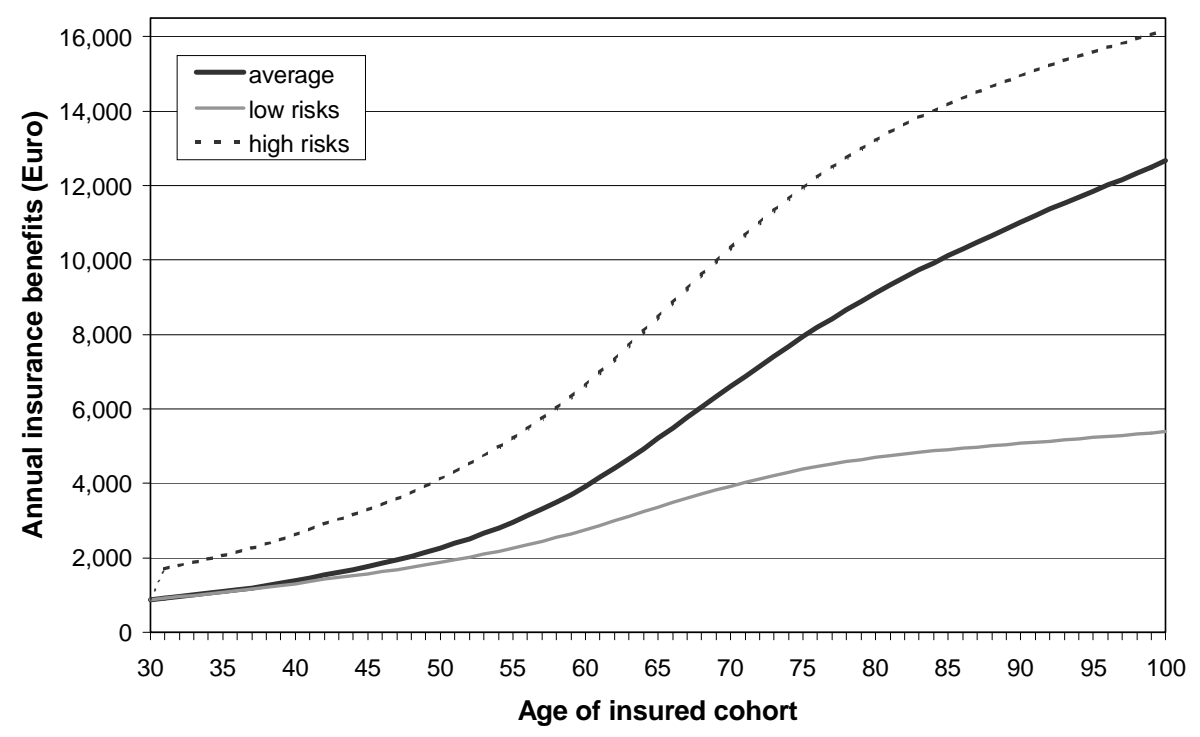

Figure 2: Health insurance benefits by risk type

males. With a less steep increase of expected benefits, pre-funding for future benefits is less important than in the baseline case, which has a strong impact on the results. Finally, we return to the case of males, now introducing some variation with respect to the age of entry, as it turns out that the length of the potential accumulation period is also important for the transferable share of total ageing provisions.

\subsection{Males (baseline case)}

Figure 3 summarises how a cohort of 30-year old low-risk males will developboth in terms of their numbers and their structure by health status - over the maximum length of the contract period. Over time, the cohort size shrinks to 1.9 per cent of the original population until these individuals reach age 100. We assume that the cohort dies out at the end of this year. Among those who survive, there is a growing portion of individuals in bad health, facing expected health cost that are considerably higher than those for good risks at the same age.

Annual total real premiums are determined in such a way that they are 


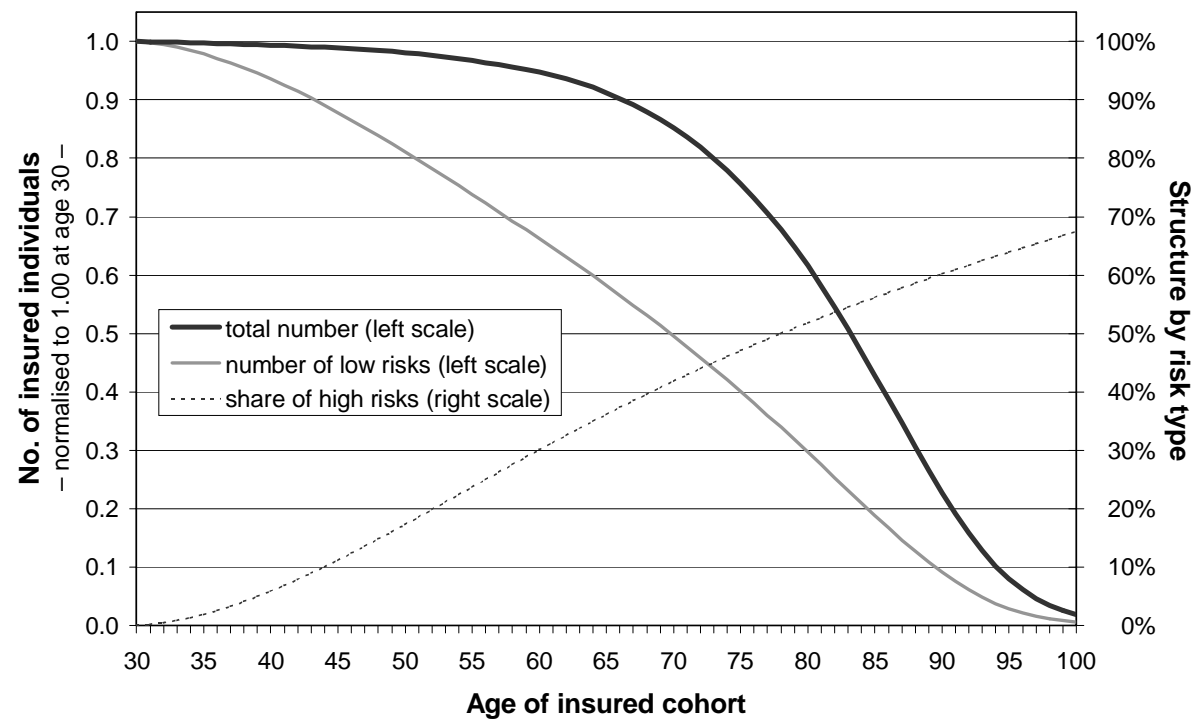

Figure 3: Evolution of the cohort of insured individuals

constant over the total contract period. During the early years, the level premium $\bar{P}_{30}$ will exceed current average health costs, while in later years it can be substantially lower. Surpluses accruing initially are accumulated as ageing provisions which are also nourished from two other sources: returns to invested funds, plus the bequests involved in redistributing the ageing provisions of individuals who die in a given year.

Figure 4 illustrates the development of all these transactions over time. It turns out that a level premium of about 2,760 Euro is enough to cover current expected health costs which, on average, are increasing from 871 Euro to 12,666 Euro a year in our baseline case. Premiums fall short of current health costs starting from age 54, but fund yields and within-cohort bequests ensure that total ageing provisions - measured per capita of insured individuals who survive - keep growing until the individuals reach age 67. Afterwards, they start decreasing at accelerating speed. As mortality gets substantially higher with age, bequests become more important when individuals are aged 80 or over. Nevertheless, funds are declining very rapidly then until they are fully exhausted at age 100 .

As indicated before, the total ageing provisions can be decomposed into 


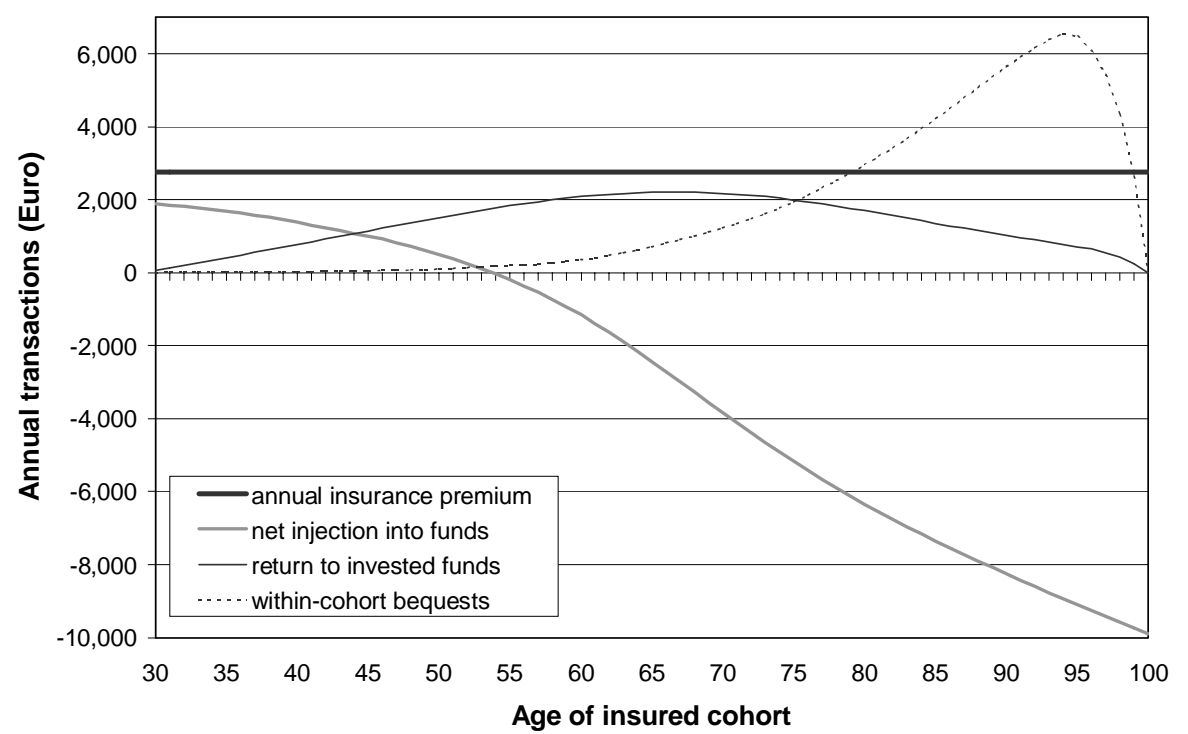

Figure 4: Lifetime contracts with constant premiums

a capital stock related to the premium insurance and funds that finance the annuity. This is done by reconstructing the lifetime contract with a level premium by a guaranteed-renewability arrangement, combined with an annnuitised life insurance. Figure 5 shows the development of shortterm health insurance premiums of low risks, average insurance benefits, and the premiums in a contract with guaranteed renewability, constant total premiums of course being identical with those displayed in Figure 4. Figure 6 illustrates the time profile of total ageing provisions per capita in a Germantype health insurance contract and the shares that are attributable to the premium insurance and the annuity insurance, respectively.

On a per-capita basis, total ageing provisions that have to be accumulated for a male individual entering the contract at age 30 peak at about 66,300 Euro when the cohort reaches age 67 and then decline. For the decomposition into two separate stocks of funds, two aspects are particularly important. Our assumptions regarding the relevant probabilities of transition imply that the risk of a change in health status is rather low at early stages of the contract period. At the same time, health costs for males show a strong age-related trend even for those who are good risks throughout. The consequence is that 


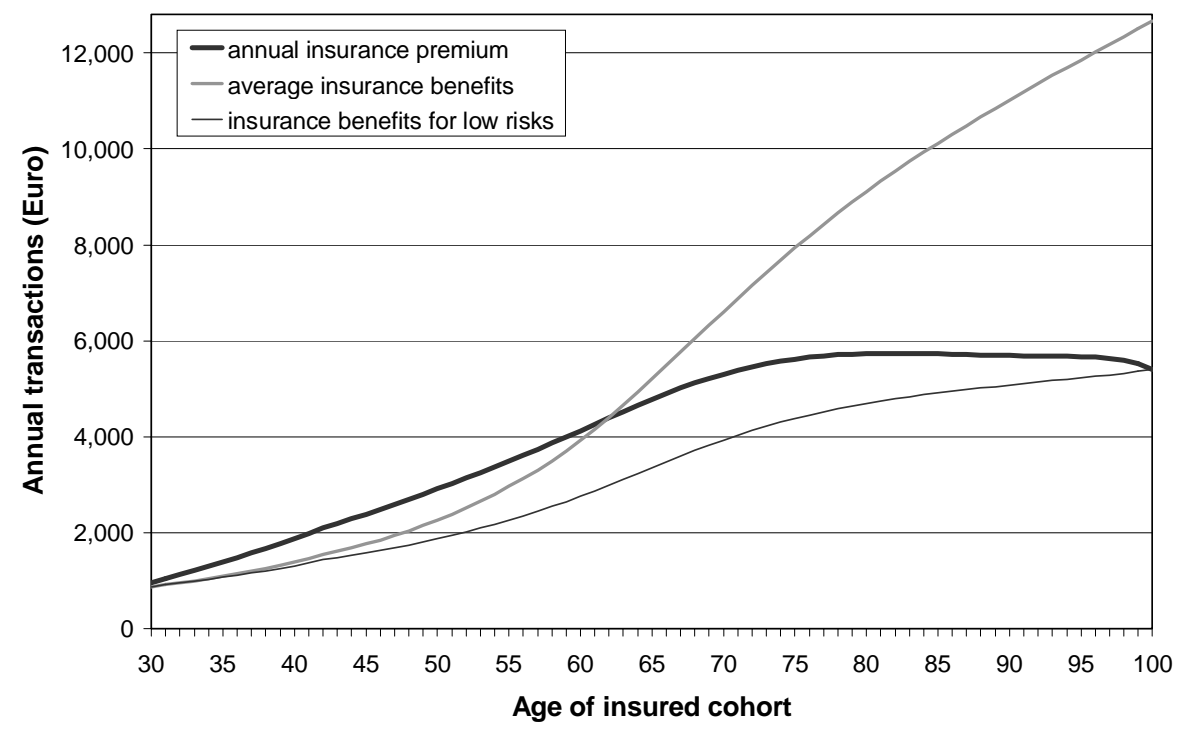

Figure 5: Contracts with guaranteed renewability

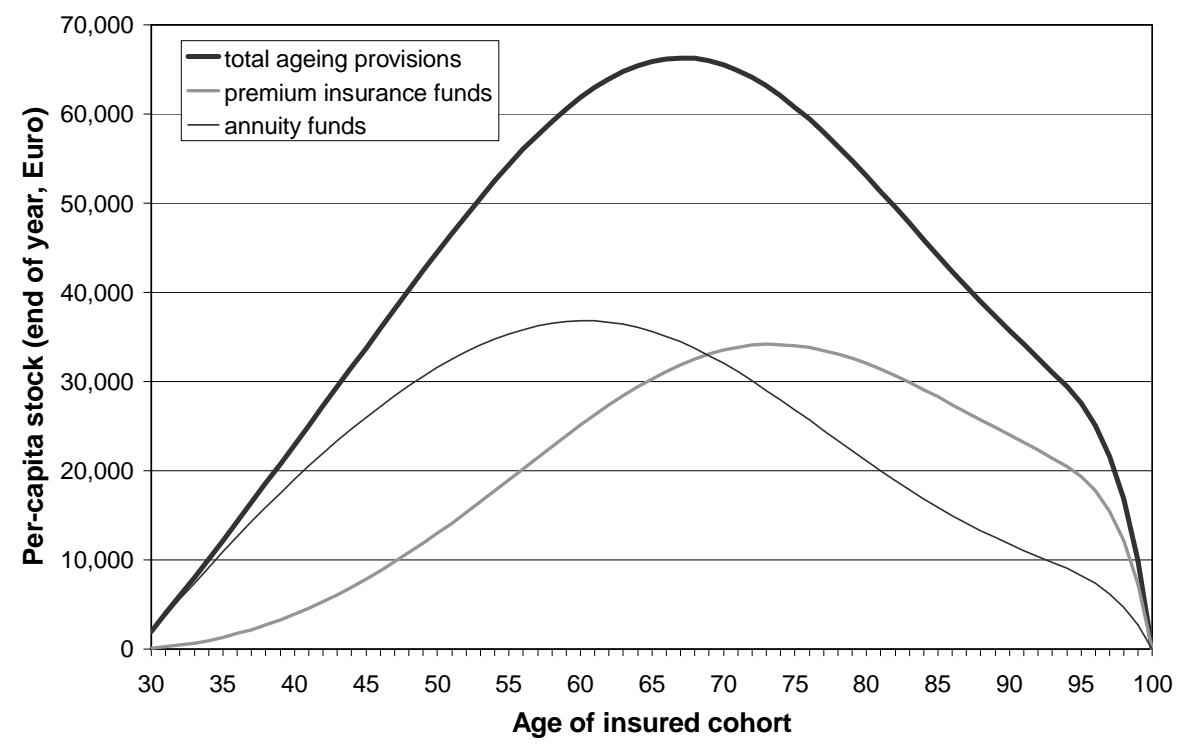

Figure 6: Decomposition of ageing provisions 


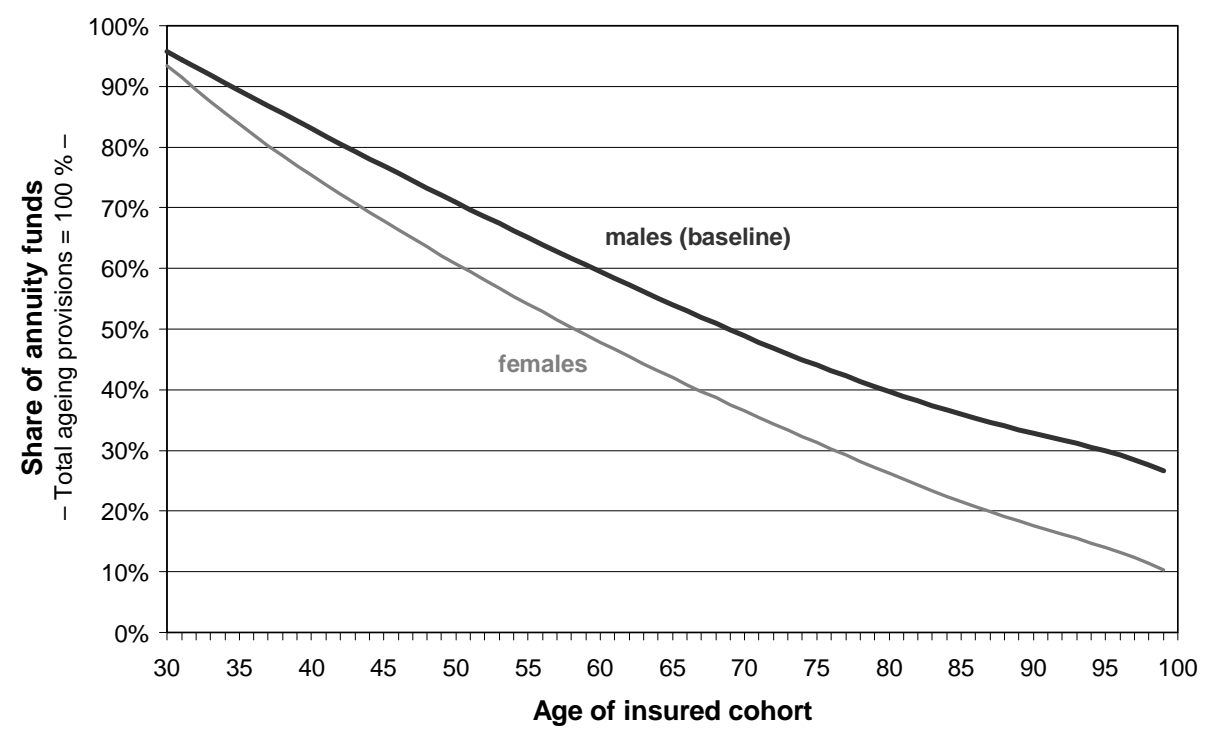

Figure 7: Share of annuity funds (males vs females)

the timing of the accumulation and decumulation of funds is significantly different for the two components. Stocks that are needed to fund the annuity reach their peak at about 36,800 Euro when individuals are aged 60, well ahead of the maximum of total provisions, while stocks that belong to the premium insurance peak at 34,100 Euro when individuals are aged 73. Since the fraction of beneficiaries in the premium insurance is increasing over time, the share of annuity funds in total ageing provisions is constantly declining with age. In our baseline simulation, it is in fact declining in an almost linear fashion from 95.7 per cent of total provisions at age 30 to 26.6 per cent at age 99 (see Figure 7).

\subsection{Females}

Things are not fundamentally different when we turn to using mortality rates and cost profiles for females in our simulations. However, differences in the age-related profile of health insurance benefits shown in Figure 1 have some bearing on our results.

We consider a cohort of females who enter private health insurance as low 
risks at age 30 , where 4.7 per cent survive until they reach age 100 . Figure 1 indicates that, when assessed in terms of lifetime present values, average health costs for females are higher than those for males. In addition, their profile is clearly less steep - a feature that carries through to the profiles attributed to good risks and bad risks, respectively, using the procedures explained in section 3. For individuals who are low risks (in brackets: high risks), these risk-specific profiles increase from 1,859 Euro (3,458 Euro) at age 30 to 4,192 Euro (12,560 Euro) at age 100, implying that the spread between risk types is smaller at any given point in time and that purely age-related trends are weaker than in the baseline simulations.

As a consequence of these deviations, the time-invariant level premium is substantially higher for females than for males, amounting to about 3,540 Euro a year. Total ageing provisions made in health insurance contracts are lower than in the baseline case. Furthermore, the changes also affect the timing of accumulation and decumulation and the structure of total funds.

It turns out that total ageing provisions per capita of surviving individuals peak at about 54,100 Euro when individuals reach age 67 . Funds that can be attributed to the annuity reach their peak at about 24,600 Euro when individuals are aged 57, while funds accumulated for the premium insurance peak at 34,450 Euro when individuals are aged 73. At each point in time, the share of annuity funds in total ageing provisions turns out to be lower than in the baseline case of males, while it always remains positive throughout the contract period. Figure 7 shows that the share of annuity funds declines from about 93 per cent at age 30 to 10 per cent at age 99 .

\subsection{Variation of the age of entry}

The precise age of entry is obviously important for the process of accumulating and decumulating ageing provisions in general and the funds related to the annuity that smoothes premiums over time in particular. Therefore, in addition to the two scenarios considered so far, we also introduce some variation with respect to this parameter, now looking at males who enter the contract aged 40,50 , and 60 , respectively.

Figure 2 illustrates that, even for low-risk types in each of these categories, there are considerable age-related differences in health costs between the age of entry and the end of the contract period. The same holds for the premium profile for contracts with guaranteed renewability (see Figure 5). On the other hand, the relative importance of measures applied to smoothing these 


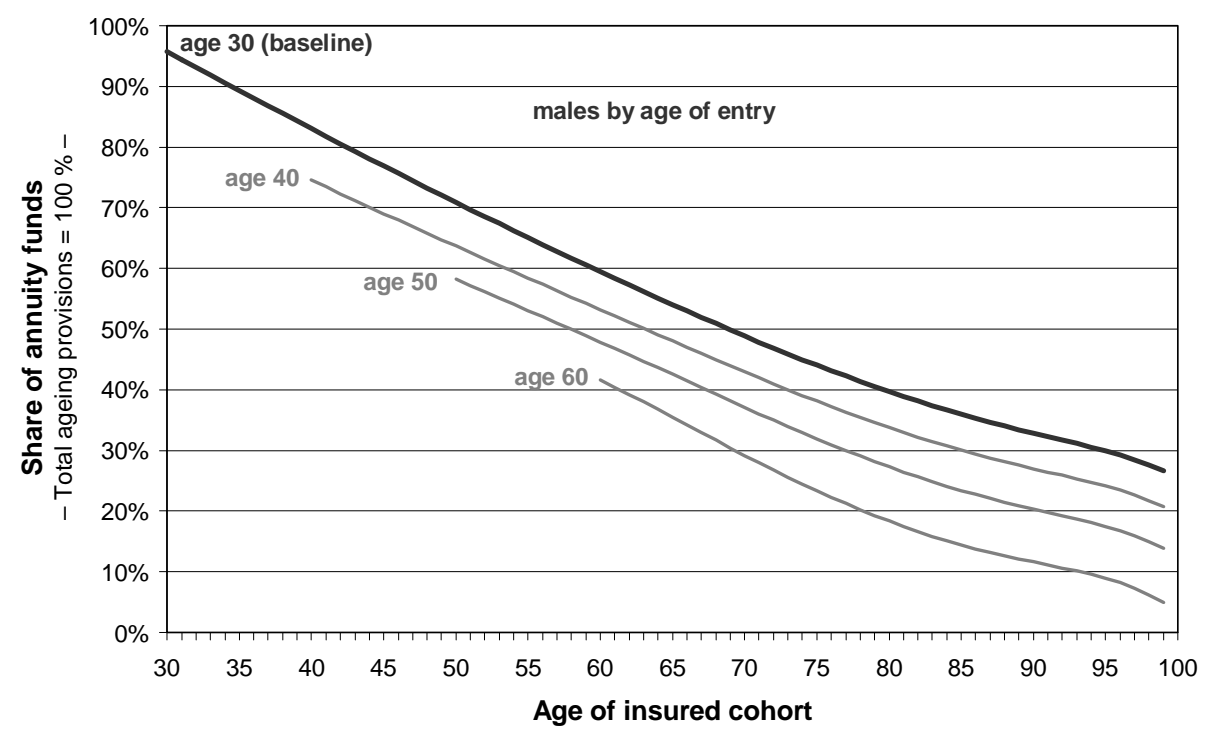

Figure 8: Share of annuity funds by age of entry (males)

differences must be expected to decrease the more the effective age of entry moves up the scale. This happens because the number of years with very low premiums in a guaranteed-renewability arrangement is reduced. Hence, some years are missing in which a high fraction of the constant level premium serves the annuity function. As a consequence, the share of annuity funds in total ageing provisions should decline with the age of entry.

Our calculations confirm this expectation. Again, we construct cohorts of individuals aged 40,50, and 60, respectively, who enter insurance as low risks and then develop over time as implied in our assumptions regarding mortality rates and transitions in health status. For each of these cohorts, we can consistently use the relevant part of the "low-risk" graph in Figure 2 as representing health costs for those who are in good health throughout. Transition probabilities and cost differentials assumed in the baseline case then give us the time profile of average health costs. The level premium is based on the present value of expected health care costs of a low risk which coincides with the present value of average health costs, differentiated by the age of entry in each new scenario. The premium profile of contracts with guaranteed renewability remains unchanged. 
With a variable age of entry, we still find that there is always a positive fraction of total ageing provisions which can be attributed to the annuity. Yet, the share of these funds which could be transferred to another insurer is smaller for 50-year olds who entered the contract at age 40 than it is for those who entered the contract at age 30. Figure 8 shows that this result goes through for any other combination of current age and age at entry. For example, the share of annuity funds for males entering at age 50 goes down from about 58 per cent at age 50 to 14 per cent at age 99 . Note that, given the data and parameters we used for our simulation, the decline of the share of transferable ageing provisions once again is almost linear.

\section{Concluding discussion}

The main message of this paper is that the share of annuity funds in individual lifetime health insurance contracts with a level premium declines in age and age of entry into the contract, and it is smaller for females than for males. It always remains positive, implying that a substantial share of ageing provisions could be made portable across insurers without harming those left behind with the initial insurer. The main reason for the decline in age lies in the fact that the share of beneficiaries in the premium insurance is increasing over time.

The differences between men and women that show up in our simulations may be somewhat exaggerated. In fact, the less steep time profile of average insurance benefits for females can also be explained by smaller transition probabilities into the high-risk state. In this case, the weight of the premium insurance would become smaller, while the profile of total ageing provisions is unchanged. Though modifications along these lines would bring the shares of funds related to the annuity closer to the male profile, implausible parameter values would have to be assumed to fully offset the gender-specific differences.

These considerations also shed light on what happens if other parameters of the model are changed. Reducing either the probabilities of transition into the high-risk state or the cost differential between high risks and low risks decreases the weight of the premium insurance and therefore raises the share of ageing provisions related to the annuity. Changes in mortality rates or the interest rate are quite important for the volume of total ageing provisions. Yet, they will have only a modest impact on the shares of premium insurance and annuity funds. Another realistic variation may assume that losing the 
low-risk status is also associated with a drop in life expectancy. In this case, high risks in terms of the short-term health insurance would constitute low risks with respect to the annuity. Provided that low risks in the short-term health insurance still represent low risks in the combined contract, the share of transferable ageing provisions would then be higher than the share of the annuity funds per capita.

A substantial problem arises from the phenomenon of unexpected permanent cost shocks hitting the entire cohort from time to time. Technological progress in the health care sector, high sectoral inflation rates, and rising life expectancy have caused regular increases in real insurance premiums in the past. In this event, the components of the ageing provisions turn out to be smaller than necessary. Since those who have already turned into high risks have to be protected against losses from risk segmentation through low risks leaving the insurer, part of the capital stock accumulated for the annuity has to be reassigned to the premium insurance. In other words, the estimated shares of transferable ageing provisions in our simulations are systematically overstated. In the case of German private health insurance, a partial solution for this problem can be found in a recent regulation requiring insurers to collect a surcharge of 10 per cent on gross premiums, the additional capital stock being meant to reduce premiums after age 65. Applying our decomposition into premium insurance and annuity insurance once again shows that a major fraction of the additional capital stock would have to be assigned to the annuity function. Only a small portion has to be used to offset the deficit in the premium insurance. Therefore, combining the additional capital stock with total ageing provisions and assuming moderate cost shocks, the shares of annuity insurance in the aggregate capital stock tend to be close to the profiles derived here.

All in all, our considerations suggest that a simple formula could be devised, indicating how much of the ageing provisions accumulated for a given individual could be made portable across insurers. Essentially, the rule would be based on individual characteristics that are very easy to verify, namely current age, age at entry, and gender. 


\section{References}

Bundesaufsichtsamt für das Versicherungswesen (BAV), 2000, Krankenversicherung. Neue Sterbetafel in der PKV, VerBAV, 49: 171-172.

Bundesanstalt für Finanzdienstleistungsaufsicht (BaFin), 2002, Krankenversicherung. Wahrscheinlichkeitstafeln 2001, VerBaFin, 51: 297-321.

Cochrane, J., 1995, Time-Consistent Health Insurance, Journal of Political Economy, 103: 445-473.

Dowd, B., and R. Feldman, 1992, Insurer Competition and Protection from Risk Redefinition in the Individual and Small Group Health Insurance Market, Inquiry, 29: 148-157.

Frick, K., 1998, Consumer Capital Market Constraints and Guaranteed Renewable Insurance, Journal of Risk and Uncertainty, 16: 271-278.

Hendel, I., and A. Lizzeri, 2003, The Role of Commitment in Dynamic Contracts: Evidence from Life Insurance, Quarterly Journal of Economics, 118: 299-327.

Herring, B., and M. Pauly, 2003, Incentive-Compatible Guaranteed Renewable Health Insurance, NBER Working Paper No. 9888, Cambridge.

Kifmann, M., 2002, Insuring Premium Risk in Competitive Health Insurance Markets (Tübingen: Mohr Siebeck).

Meier, V., 2003, Efficient Transfer of Aging Provisions in Private Health Insurance, CESifo Working Paper No. 862, Munich.

Pauly, M., H. Kunreuther, and R. Hirth, 1995, Guaranteed Renewability in Insurance, Journal of Risk and Uncertainty, 10: 143-156. 


\section{CESifo Working Paper Series}

(for full list see www.cesifo.de)

1051 Carlos Fonseca Marinheiro, Output Smoothing in EMU and OECD: Can We Forego Government Contribution? A Risk Sharing Approach, October 2003

1052 Olivier Bargain and Nicolas Moreau, Is the Collective Model of Labor Supply Useful for Tax Policy Analysis? A Simulation Exercise, October 2003

1053 Michael Artis, Is there a European Business Cycle?, October 2003

1054 Martin R. West and Ludger Wößmann, Which School Systems Sort Weaker Students into Smaller Classes? International Evidence, October 2003

1055 Annette Alstadsaeter, Income Tax, Consumption Value of Education, and the Choice of Educational Type, October 2003

1056 Ansgar Belke and Ralph Setzer, Exchange Rate Volatility and Employment Growth: Empirical Evidence from the CEE Economies, October 2003

1057 Carsten Hefeker, Structural Reforms and the Enlargement of Monetary Union, October 2003

1058 Henning Bohn and Charles Stuart, Voting and Nonlinear Taxes in a Stylized Representative Democracy, October 2003

1059 Philippe Choné, David le Blanc and Isabelle Robert-Bobée, Female Labor Supply and Child Care in France, October 2003

1060 V. Anton Muscatelli, Patrizio Tirelli and Carmine Trecroci, Fiscal and Monetary Policy Interactions: Empirical Evidence and Optimal Policy Using a Structural New Keynesian Model, October 2003

1061 Helmuth Cremer and Pierre Pestieau, Wealth Transfer Taxation: A Survey, October 2003

1062 Henning Bohn, Will Social Security and Medicare Remain Viable as the U.S. Population is Aging? An Update, October 2003

1063 James M. Malcomson, Health Service Gatekeepers, October 2003

1064 Jakob von Weizsäcker, The Hayek Pension: An efficient minimum pension to complement the welfare state, October 2003

1065 Joerg Baten, Creating Firms for a New Century: Determinants of Firm Creation around 1900, October 2003 
1066 Christian Keuschnigg, Public Policy and Venture Capital Backed Innovation, October 2003

1067 Thomas von Ungern-Sternberg, State Intervention on the Market for Natural Damage Insurance in Europe, October 2003

1068 Mark V. Pauly, Time, Risk, Precommitment, and Adverse Selection in Competitive Insurance Markets, October 2003

1069 Wolfgang Ochel, Decentralising Wage Bargaining in Germany - A Way to Increase Employment?, November 2003

1070 Jay Pil Choi, Patent Pools and Cross-Licensing in the Shadow of Patent Litigation, November 2003

1071 Martin Peitz and Patrick Waelbroeck, Piracy of Digital Products: A Critical Review of the Economics Literature, November 2003

1072 George Economides, Jim Malley, Apostolis Philippopoulos, and Ulrich Woitek, Electoral Uncertainty, Fiscal Policies \& Growth: Theory and Evidence from Germany, the UK and the US, November 2003

1073 Robert S. Chirinko and Julie Ann Elston, Finance, Control, and Profitability: The Influence of German Banks, November 2003

1074 Wolfgang Eggert and Martin Kolmar, The Taxation of Financial Capital under Asymmetric Information and the Tax-Competition Paradox, November 2003

1075 Amihai Glazer, Vesa Kanniainen, and Panu Poutvaara, Income Taxes, Property Values, and Migration, November 2003

1076 Jonas Agell, Why are Small Firms Different? Managers' Views, November 2003

1077 Rafael Lalive, Social Interactions in Unemployment, November 2003

1078 Jean Pisani-Ferry, The Surprising French Employment Performance: What Lessons?, November 2003

1079 Josef Falkinger, Attention, Economies, November 2003

1080 Andreas Haufler and Michael Pflüger, Market Structure and the Taxation of International Trade, November 2003

1081 Jonas Agell and Helge Bennmarker, Endogenous Wage Rigidity, November 2003

1082 Fwu-Ranq Chang, On the Elasticities of Harvesting Rules, November 2003

1083 Lars P. Feld and Gebhard Kirchgässner, The Role of Direct Democracy in the European Union, November 2003 
1084 Helge Berger, Jakob de Haan and Robert Inklaar, Restructuring the ECB, November 2003

1085 Lorenzo Forni and Raffaela Giordano, Employment in the Public Sector, November 2003

1086 Ann-Sofie Kolm and Birthe Larsen, Wages, Unemployment, and the Underground Economy, November 2003

1087 Lars P. Feld, Gebhard Kirchgässner, and Christoph A. Schaltegger, Decentralized Taxation and the Size of Government: Evidence from Swiss State and Local Governments, November 2003

1088 Arno Riedl and Frans van Winden, Input Versus Output Taxation in an Experimental International Economy, November 2003

1089 Nikolas Müller-Plantenberg, Japan’s Imbalance of Payments, November 2003

1090 Jan K. Brueckner, Transport Subsidies, System Choice, and Urban Sprawl, November 2003

1091 Herwig Immervoll and Cathal O'Donoghue, Employment Transitions in 13 European Countries. Levels, Distributions and Determining Factors of Net Replacement Rates, November 2003

1092 Nabil I. Al-Najjar, Luca Anderlini \& Leonardo Felli, Undescribable Events, November 2003

1093 Jakob de Haan, Helge Berger and David-Jan Jansen, The End of the Stability and Growth Pact?, December 2003

1094 Christian Keuschnigg and Soren Bo Nielsen, Taxes and Venture Capital Support, December 2003

1095 Josse Delfgaauw and Robert Dur, From Public Monopsony to Competitive Market. More Efficiency but Higher Prices, December 2003

1096 Clemens Fuest and Thomas Hemmelgarn, Corporate Tax Policy, Foreign Firm Ownership and Thin Capitalization, December 2003

1097 Laszlo Goerke, Tax Progressivity and Tax Evasion, December 2003

1098 Luis H. B. Braido, Insurance and Incentives in Sharecropping, December 2003

1099 Josse Delfgaauw and Robert Dur, Signaling and Screening of Workers' Motivation, December 2003

1100 Ilko Naaborg,, Bert Scholtens, Jakob de Haan, Hanneke Bol and Ralph de Haas, How Important are Foreign Banks in the Financial Development of European Transition Countries?, December 2003 
1101 Lawrence M. Kahn, Sports League Expansion and Economic Efficiency: Monopoly Can Enhance Consumer Welfare, December 2003

1102 Laszlo Goerke and Wolfgang Eggert, Fiscal Policy, Economic Integration and Unemployment, December 2003

1103 Nzinga Broussard, Ralph Chami and Gregory D. Hess, (Why) Do Self-Employed Parents Have More Children?, December 2003

1104 Christian Schultz, Information, Polarization and Delegation in Democracy, December 2003

1105 Daniel Haile, Abdolkarim Sadrieh and Harrie A. A. Verbon, Self-Serving Dictators and Economic Growth, December 2003

1106 Panu Poutvaara and Tuomas Takalo, Candidate Quality, December 2003

1107 Peter Friedrich, Joanna Gwiazda and Chang Woon Nam, Development of Local Public Finance in Europe, December 2003

1108 Silke Uebelmesser, Harmonisation of Old-Age Security Within the European Union, December 2003

1109 Stephen Nickell, Employment and Taxes, December 2003

1110 Stephan Sauer and Jan-Egbert Sturm, Using Taylor Rules to Understand ECB Monetary Policy, December 2003

1111 Sascha O. Becker and Mathias Hoffmann, Intra-and International Risk-Sharing in the Short Run and the Long Run, December 2003

1112 George W. Evans and Seppo Honkapohja, The E-Correspondence Principle, January 2004

1113 Volker Nitsch, Have a Break, Have a ... National Currency: When Do Monetary Unions Fall Apart?, January 2004

1114 Panu Poutvaara, Educating Europe, January 2004

1115 Torsten Persson, Gerard Roland, and Guido Tabellini, How Do Electoral Rules Shape Party Structures, Government Coalitions, and Economic Policies? January 2004

1116 Florian Baumann, Volker Meier, and Martin Werding, Transferable Ageing Provisions in Individual Health Insurance Contracts, January 2004 